\title{
Influence of The Compression Ratio and Ignition Timing On CB150R Engine Performance with 85\% Bioethanol Gasoline Blended Fuel
}

\author{
Yuli Mafendro D. E. S ${ }^{1}$, Bambang Sudarmanta ${ }^{1}$, Marthen Paloboran ${ }^{2}$
}

\begin{abstract}
Subtitution of the fuel type in the gasoline engine will change the setting The engine parameters as well as modify it to minimize engine performance degradation And increased exhaust emissions. Utilization of ethanol (85\% vol.) - gasoline (15\% vol.) The combination (E-85) for the gasoline engine requires some machine modifications and setting parameters due to differences in properties and characters between ethanol and gasoline. This study aims to test the effect of ignition timing and compression ratio on the performance of the engine and emission gas emissions. Ignition time varies between 16-24 Before Top Dead Center (BTDC) d. While the compression ratio variation consists of 11 (standart); 12, 12.5 and 13: 1. It was found that advancing the ignition time range $1^{\circ}-24^{\circ}$ BDTC with 13: 1 compression ratio can increase the performance of torque, bmep, and thermal efficiency respectively $7.94 \%, 5,82 \%$ and $1.6 \%$ respectively, and a decrease of emissions of co and hc respectively $56.6 \%$ and $0.6 \%$ when compared with the performance of standard gasoline-fueled engines (E0).
\end{abstract}

Keywords_-Bioethanol 85\% (E85), Compretion Ratio, Ignition Timing, Perfomance Engine.

\section{INTRODUCTION}

$\mathrm{E}$ nergy policies around the world to reduce the -1 emissions and greenhouse effect caused by fossil fuel combustion remains a concern to researchers. Alternative fuels, as defined by Energy ACT Policy 1992 (EPACT), including alcohol (Biomethanol, bioethanol and others), natural gas, Liquified petroleum gas, hydrogen, coal derived liquidmFuel, biofuels (including biodiesel, synthesis gas and others), And electricity. This fuel is used wordwide in a various stationary and mobile applications [1]. They A great power in efforts to reduce fossil fuels Consumption and environmental impact (including harmful Pollutants and exhaust emissions) in transport Sector.

Although ethanol has been used as an SI engine fuel since the19 th century, it is not used widely because of its high cost. Nonetheless, ethanol has been and is being used as an additive to increase octane number and decrease exhaust emissions. Ethanol is commonly used in Brazil and the USA. Recently, almost all EU countries established incentives for the use of ethanol to decrease their energy dependence [2]-[5].

Some fuel properties of ethanol, such as the octane number, heating to value, latent heat of vaporisation, flame velocity, specific gravity, Reid vapour pressure and distillation curve, are quite different from those of gasoline. Therefore, an understanding of the effects of these

\footnotetext{
${ }^{1}$ Yuli Mafendro D. E.S, Bambang Sudarmanta are with Department of Mechanical Engineering, Faculty of Industrial Engineering, Institut Teknologi Sepuluh Nopember (ITS), Kampus ITS Sukolilo, Surabaya 60111, Indonesia. E-mail: yulimafendror@gmail.com; sudarmanta@me.its.ac.id;

${ }^{2}$ Marthen Paloboran is with Department of Automotivel Engineering, Faculty of Engineering, Universitas Negeri Makasar, Kampus UNM Makasar, 90242, Indonesia. E-mail: marthen.paloboran@unm.ac.id.
}

properties on the combustion and performance of SI engines is vital [6].

Many researchers who have conducted experiments to determine the effect of ethanol on the torque and power of engines have reported that ethanol blending improves these performance parameters [7]-[9]. Giroldo et al. [7], in their experiments with E25 (75\% gasoline - 25\% ethanol), found $5.7 \%$ and $6.2 \%$ increases in the peak values of the engine power and torque, respectively. In a simulation study, Dai et al. [8] compared the performance of ethanol and gasoline and reported a 3\% increase in thermal efficiency and a $4 \%$ increase in shaft power. The authors validated the results of the simulation with experimental data. Cowart et al. conducted some experiments and observed a $4 \%$ increase in engine torque with ethanol in comparison to gasoline. Sudarmanta et all [9] compared the performance of ethanol $50 \%$ and gasoline and reported The use of E50 fuel, at the compression ratio is 11.6 can improve brake torque, power and mep respectively by $3,68 \%, 4.58 \%$ and $3.68 \%$ as compared to using pure gasoline at a compression ratio of 9,6 . While the influence of adding compression ratio at the E50 can reduce bsfc by $13,42 \%$ and increase thermal efficiency by 14, $67 \%$. Palaboran et all [10] do research conducted by mapping the injection duration at a high compression ratio. The results showed increased torque, power and BMEP when compression ratio increased. By mapping the injection duration, all the performances parameters increased gradually up to the maximum speed. Moreover, the $\mathrm{CO}$ and $\mathrm{HC}$ emission decreased significantly by this method. However, the SFC and thermal efficiency of ethanol were inferior to gasoline. It was because ethanol had lower heating value than that of gasoline. 


\section{METHOD}

This research will be done by using experimental method on Engine Honda CB150R. The fuel to be used in this test is twofold type. For data collection, fuel used is gasoline, while for taking the test data with progamble ECU, the fuel used is ethanol E85 (85\% ethanol $+15 \%$ Gasoline). The variation is mapping Engine ignition angles vary from $16^{\circ}$ $28^{\circ}$ BTDC with engine speeds varying between $2000 \mathrm{rpm}$ with an increase of every $1000 \mathrm{rpm}$ to $8000 \mathrm{rpm}$ at 12: 1 compression ratio, 12.5: 1, and 13:1. Fuel characteristics and Engine specifications are given in table 1 and table 2.

TABLE 1. CHARACTERISTIC OF FUEL

\begin{tabular}{lcccc}
\hline \multicolumn{1}{c}{ Properties } & Unit & Gasoline & Ethanol & E85 \\
\hline SG & & 0.7391 & 0.813 & 0.801 \\
Nilai Kalor & Kkal/kg & 10674.6 & 4275.8 & 4640 \\
RON & - & $91-98$ & \pm 108 & $>111$ \\
RVP & $\mathrm{KPA}$ & 5.59 & 2.35 & 5.46 \\
Density & $\mathrm{Kg} / \mathrm{m}^{3}$ & 764 & 790 & 801 \\
Stoichiometric air/fuel & - & 14,7 & 9 & 9,8 \\
Lower Heating Value & $\mathrm{KJ} / \mathrm{Kg}$ & 42,9 & 26,7 & 29,2 \\
\hline \hline
\end{tabular}

\begin{tabular}{ll}
\multicolumn{2}{c}{ TABLE 2. ENGINE SPESIPICATION } \\
\hline \hline \multicolumn{2}{c}{ Spesification } \\
\hline Engine Type & HONDA CBR 150R \\
Number of Cylinder & 1 \\
Bore x Stroke & $63,5 \times 47,2$ \\
Displacement Volume & $150 \mathrm{cc}$ \\
Compression Ratio & 11 \\
Control System & Progrannable ECU \\
Fuel Intake System & Port Injection \\
Maximum Torque & $12,5 \mathrm{~kW}(17,0$ PS)/10000 rpm \\
Maximum Power & $12,5 \mathrm{~kW}(17,0$ PS)/10000 rpm \\
Coolant System & Liquid with radiator \\
\hline \hline
\end{tabular}

Water brake dynamometer with power capacity $120 \mathrm{hp}$ used in these experiments. The fuel consumption was measured by the time fuel consumption per 25 cc of fuel in a measuring glass. The emission parameters, exhaust gas temperature and air fuel ratio were measured using Stargas exhaust gas analyzer. The fuel measuring glass was fitted to Sinjai engine and it contained E50 fuel. A schematic diagram of experimental setup is shown in figure 1 .

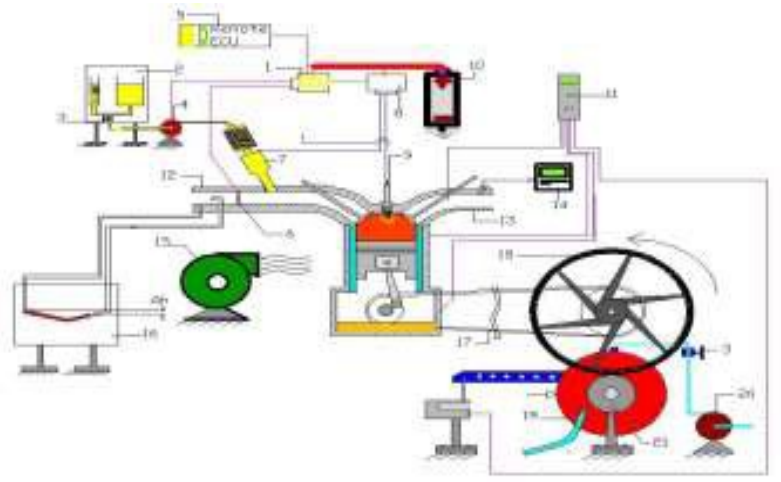

Figure 1. Experimental Scheme.

\section{RESULT AND ANALYSIS}

A. Performance analysis with gasoline fuel (E0)

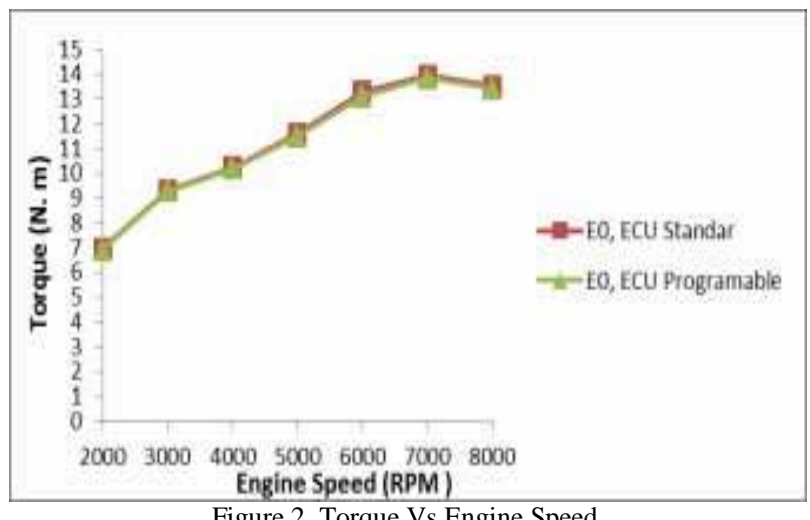

From the above data can be calculated that on lap2000 rpm, when replacing the standard ECU to the resulting progamable torque ECU is $6.776 \mathrm{~N}$.m, the decrease of torque occurred at $2.686 \%$. On lap $7000 \mathrm{rpm}$, torque generated $13.788 \mathrm{~N} . \mathrm{m}$, decrease The torque that occurs is $1.126 \%$ of the ECU standard. At the engine speed of 8000 $\mathrm{rpm}$, the torque is generated is $13.425 \mathrm{~N} . \mathrm{m}$, the decline is happening is $0.798 \%$ of the standard ECU. Although there is a decrease in torque, ECU progamamble is considered feasible to be used in this study because of the decline the torque is very small. Therefore, onsubsequent analyzes compared with E0 with the use of ECU progamable.

\section{B. Performance Analysis and Engine Exhaust Emission Bioethanol Fuel E85 with Variations Ignition Timing Each Compression Ratio}

\section{1) Torsque Analysis MBT Method (Maximum Best Torque)} (Maximum Best Torque)

From the rpm function torque chart, there is a trend torques panoramas ranging from low rotation to reach Maximum torque at a particular turn. Then torque Decreased at higher rounds. This matter Caused, the higher the engine speed then turbulence Flow into the combustion chamber will be higher and causes mixing of fuel and air The better and the fire propagation is also faster So the torque will increase. After engine speed The higher the greater the loss of losses, such as friction losses and the presence of incomplete combustion. Increasingly High engine rotation then the friction is happening too the greater it is.

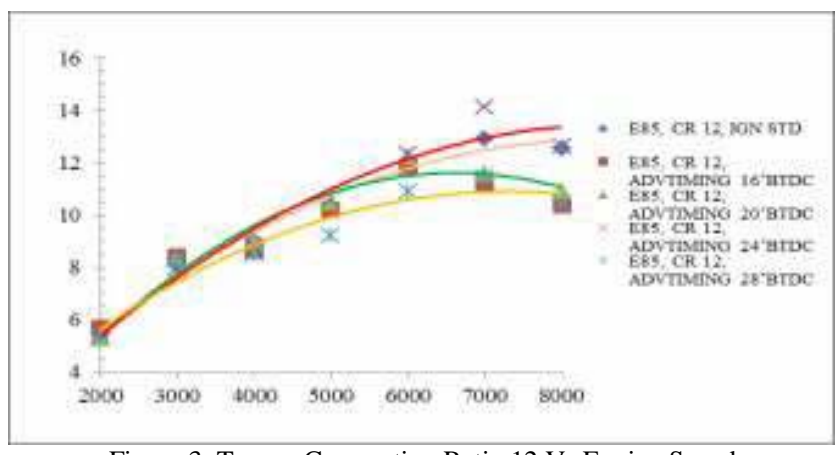

Figure 3. Torque Compretion Ratio 12 Vs Engine Speed. 


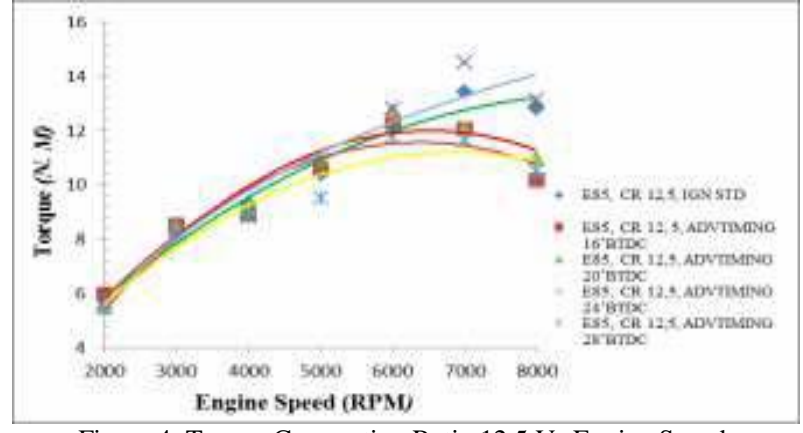

Figure 4. Torque Compretion Ratio 12,5 Vs Engine Speed.

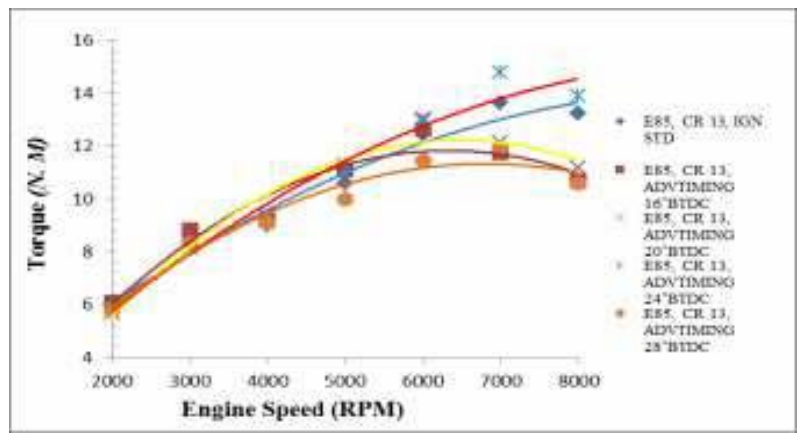

Figure 5. Torque Compretion Ratio 13 Vs Engine Speed.

After obtaining the torque data for each compression ratio, then maps the optimal ignition timing with the MBT (Maximum Best Torque) in each compression ratio. By using this MBT method, the ignition time is obtained which produces the largest torque for each engine rotation change in each variation of the compression ratio. This ignition mapping data is then stored into the remote ECU and used for data retrieval next performance. For each variation of the ratio compression, it is found that ignition timing is not has a trend. This is due to the interval of ignition timing variations are too large $4^{\circ} \mathrm{BTDC}$ between $16^{\circ} \mathrm{Up}$ to $28^{\circ}$ BTDC.

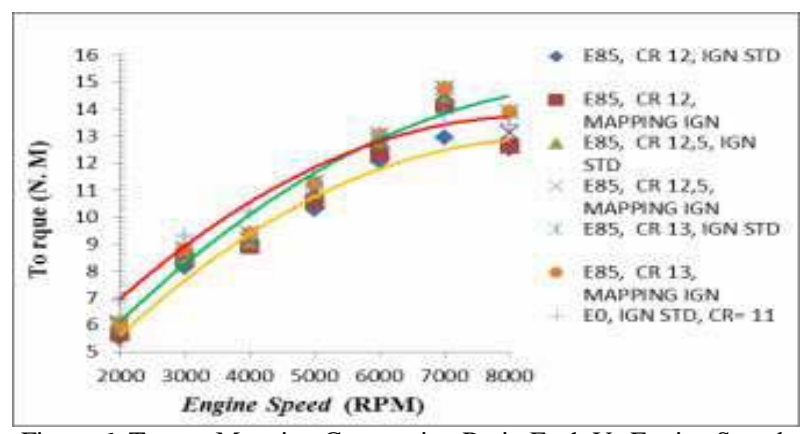

Figure 6. Torque Mapping Compretion Ratio Each Vs Engine Speed.

On mapping $16^{\circ}$ BTDC torque value experienced decrease to torque mapping ignition timing standard in all conditions of compression ratio, torque value decreased each $9.37 \%, 8.39 \%$, and $7.83 \%$. On mapping $20^{\circ}$ BTDC the torque value still decreases against torque mapping standard ignition time on all compretion ratio, torque decreases each $5.68 \%, 8.39$, and $4.39 \%$. On mapping $24^{\circ}$ BTDC torque value has increased against mapping standard ignition timing on all compression ratio, increased each $8 \%, 7.71 \%$, and $7.97 \%$. Then on the mapping ignition timing $28^{\circ}$ BTDC torque value experienced a decline that tends to be large. This is caused by too advanced ignition timing causes the process burning has not been on the ambient conditions of the combustion chamber that is too low.

\section{Beam Mean Efective Pressure (BMEP)}

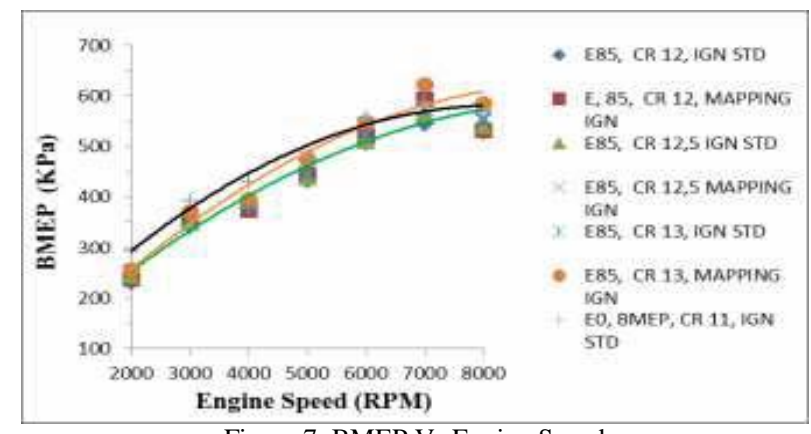

Figure 7. BMEP Vs Engine Speed

Changes in pressure occurring in the cylinders during processing burning will affect the resulting engine emissions. The magnitude pressure changes are caused by heat release during the combustion process ccompanied by expansion and compression process by the piston step in the cylinder. Variation cycle is taken into account in determining ignition timing. Change ignition timing that is too advanced or backward will have an impact on distortion of striking pressure changes from a cycle of cycles next and will affect the power and emissions generated by the engine. effective pressure the average piston is strongly influenced by the ignition timing of spark plugs. if ignition timing is not appropriate, then the piston pressure will decrease. this is also seen in the graph above. On ignition timing $16^{\circ}$ and $20^{\circ}$ BTDC has the highest pressure on low to medium rotation, however will decrease along with the increase of engine rotation tohigh rotation due to frictions and loses that occur as great as that causing the value of torque to decrease so that bmep also come down.

The result of the ignition timing mapping also increases bmep on each vasriasi of compression ratio when compared with standard engine condition using E0 fuel, bmep up $1.25 \%$ each, up $3.9 \%$ and up $5.82 \%$.

\section{Spesific Fuel Consumption}

Specific fuel consumption can be defined as flow rate fuel to obtain effective power. The value of fuel consumption specific depending on the mixture of air and internal combustible fuel burn room. With the perfect combustion, then the sfc which is getting better. Specific fuel consumption results from mapping ignition timing on all compression ratios shown by the figure below.

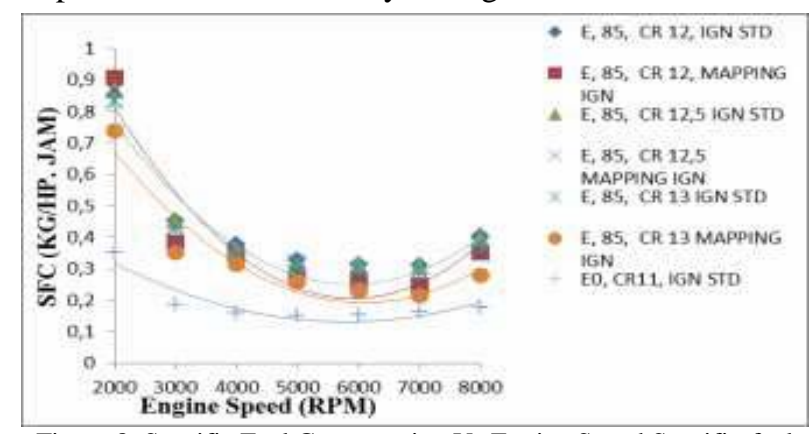

Figure 8. Spesific Fuel Consumption Vs Engine Speed Spesific fuel consumption E85 will be greater than that of 
Gasoline (E0), this is due to the low ethanol calor value of gasoline, but as the compression ratio of specific fuel ethanol consumption decreases even though it is still above the gasoline, Burn up on all compression ratios each $33,93 \%$, 30,55\%, and 23,7\%.

\section{E. Thermal Efficiency}

Thermal efficiency is a measure of the magnitude of heat energy utilization stored in the fuel to be converted into effective power on internal combustion motor. The thermal efficiency value depends on the mixture air and burning fuel in the combustion chamber. Thermal efficiency results from the best ignition timing mapping shown by the figure below.

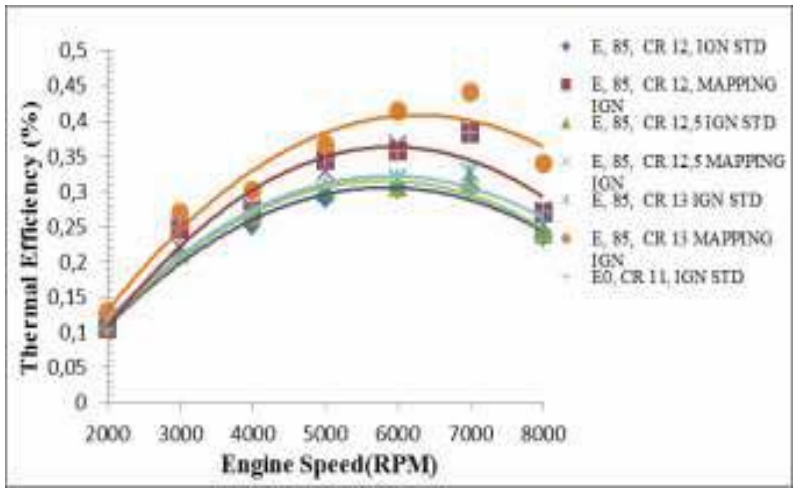

Figure 9. Thermal Efficiency Vs Engine Speed

Thermal efficiency is influenced by the amount of torque generated by the engine. With increased torque is greater then make the value of power from the engine is also greater. Meanwhile, the power generated from the engine is used for the denominator in the calculation of thermal efficiency divided by the lower calorific value (NKB) of the fuel multiplied by the fuel flow rate. So it can be concluded, the greater the value of power generated by the engine makes the value of thermal efficiency higher. Thermal efficiency E85 increase from E0 in all ratio compretion each $0,6 \%, 0,18 \%$, and $1,8 \%$.

\section{F. Analysis Exhaust Gas Emission}

1) Analysis $\mathrm{CO}$

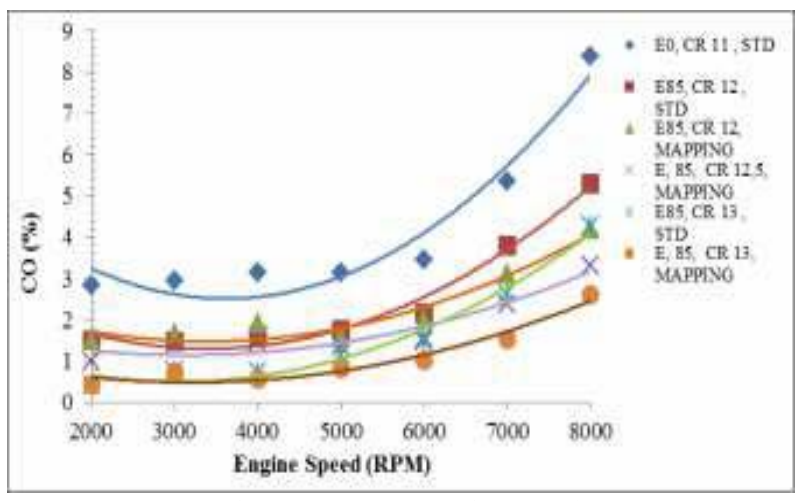

Figure 10. CO Vs Engine Speed

In the above $\mathrm{CO}$ vs rpm emission graphs, trendline tend to be obtained same for each advance ignition timing. In the graph above looks $\mathrm{CO}$ value increases with increasing engine speed. Increased $\mathrm{CO}$ emissions due to the increasingly rich mix of fuel and air. Wealth the mixture is caused by the decrease in air supply as it is getting increasingly the smaller the pressure difference between atmospheric air and cylindrical space. The average $\mathrm{CO}$ emissions produced by E0 are $4.17 \%$. By mapping ignition timing $\mathrm{CO}$ emissions decreased at all compression ratio ecah 45.39\%, 57.36\%, and 76.65\%.

2) Analysis $\mathrm{HC}$

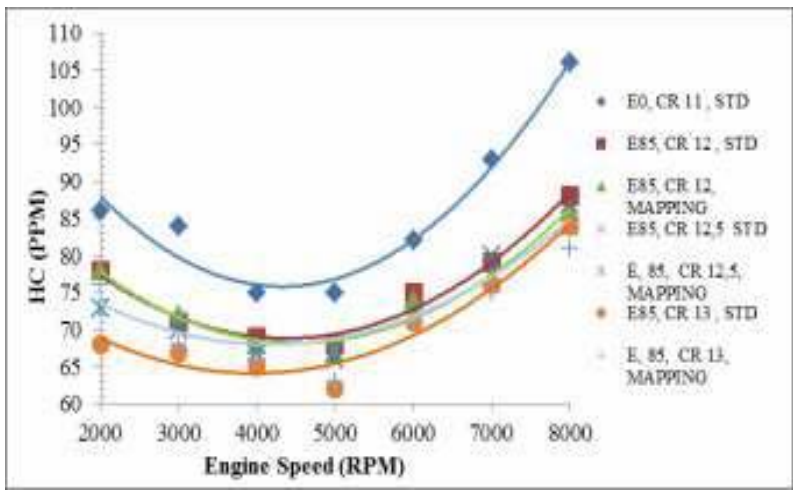

Figure 11. HC Vs Engine Speed

At low rotation $\mathrm{HC}$ emissions tend to be high and decrease as engine speed increases. After the HC emission is at its lowest point will increase until rpm is at $8000 \mathrm{rpm}$. This is due to the similarity of the amount of fuel injected to each change of degree of ignition. So the burning process tends to be the same. With the ignition timing mapping, there was a decrease of HC emission on all compression ratio each $13.1 \% 14.4 \%$ and $14.8 \%$.

\section{CONCLUSION}

The optimum performance is found in CR 13 with igniton timing $16^{\circ}-24^{\circ}$ BTDC. Where in the case of increased torque, bmep and thermal efficiency each 7.94\%, 5.82\% and $1.6 \%$ when compared with E0. Emissions generated at optimal performance decreased $\mathrm{CO}$ and $\mathrm{HC}$ levels by $56.6 \%$ and $0.6 \%$ compared to E0 emissions.

\section{ACKNOWLEDGEMENT}

The authors would like to thank Mr. Bambang Sudarmanta and Mr. Marten Paloboran for his superb technical support throughout this research.

\section{REFERENCES}

[1] B. Sudarmanta, S. Darsopuspito, and D. Sungkono, "Influence of Bioethanol-Gasoline Blended Fuel on Performance and Emissions Characteristics from Port Injection Sinjai Engine 650 cc,” Appl. Mech. Mater., vol. 493, pp. 273-280, Jan. 2014.

[2] A. K. Agarwal, "Biofuels (alcohols and biodiesel) applications as fuels for internal combustion engines," Prog. Energy Combust. Sci., vol. 33, no. 3, pp. 233-271, Jun. 2007.

[3] S. Kim and B. E. Dale, "Environmental aspects of ethanol derived from no-tilled corn grain: nonrenewable energy consumption and greenhouse gas emissions,” Biomass and Bioenergy, vol. 28, no. 5, pp. 475-489, May 2005.

[4] M. Koç, Y. Sekmen, T. Topgül, and H. S. Yücesu, "The effects of ethanol-unleaded gasoline blends on engine performance and exhaust emissions in a spark-ignition engine," Renew. Energy, vol. 34, no. 10, pp. 2101-2106, Oct. 2009.

[5] N. Jeuland, X. Montagne, and X. Gautrot, "Potentiality of Ethanol As a Fuel for Dedicated Engine," Oil Gas Sci. Technol., vol. 59, no. 6, pp. 559-570, Nov. 2004.

[6] T. Lanzer, O. F. von Meien, and C. I. Yamamoto, "A predictive 
thermodynamic model for the Brazilian gasoline,” Fuel, vol. 84, no. 9, pp. 1099-1104, Jun. 2005.

[7] R. C. Costa and J. R. Sodré, "Compression ratio effects on an ethanol/gasoline fuelled engine performance,” Appl. Therm. Eng., vol. 31, no. 2-3, pp. 278-283, Feb. 2011.

[8] M. Al-Hasan, "Effect of ethanol-unleaded gasoline blends on engine performance and exhaust emission," Energy Convers. Manag., vol. 44, no. 9, pp. 1547-1561, Jun. 2003.
[9] B. Sudarmanta, B. Junipitoyo, A. Bachtiar, K. Putra, and I. N. Sutantra, "Influence of The Compression Ratio and Ignition Timing on Sinjai Engine Performance with 50\% Bioethanol-Gasoline Blended Fuel,” ARPN J. Eng. Appl. Sci., vol. 11, no. 4, 2016.

[10] M. Paloboran, N. Sutantra, B. Sudarmanta, and R. F. Dharmawan, "Suitable injection duration of pure ethanol fuel for indonesian motorcyle at a high compression ratio," DYNA - Ing. e Ind., vol. 92, no. 5, pp. 587-592, 2017. 